\title{
Radiative forcing and climate metrics for ozone precursor emissions: the impact of multi-model averaging
}

\section{R. MacIntosh et al.}

Correspondence to: C. R. MacIntosh (c.r.macintosh@reading.ac.uk) 


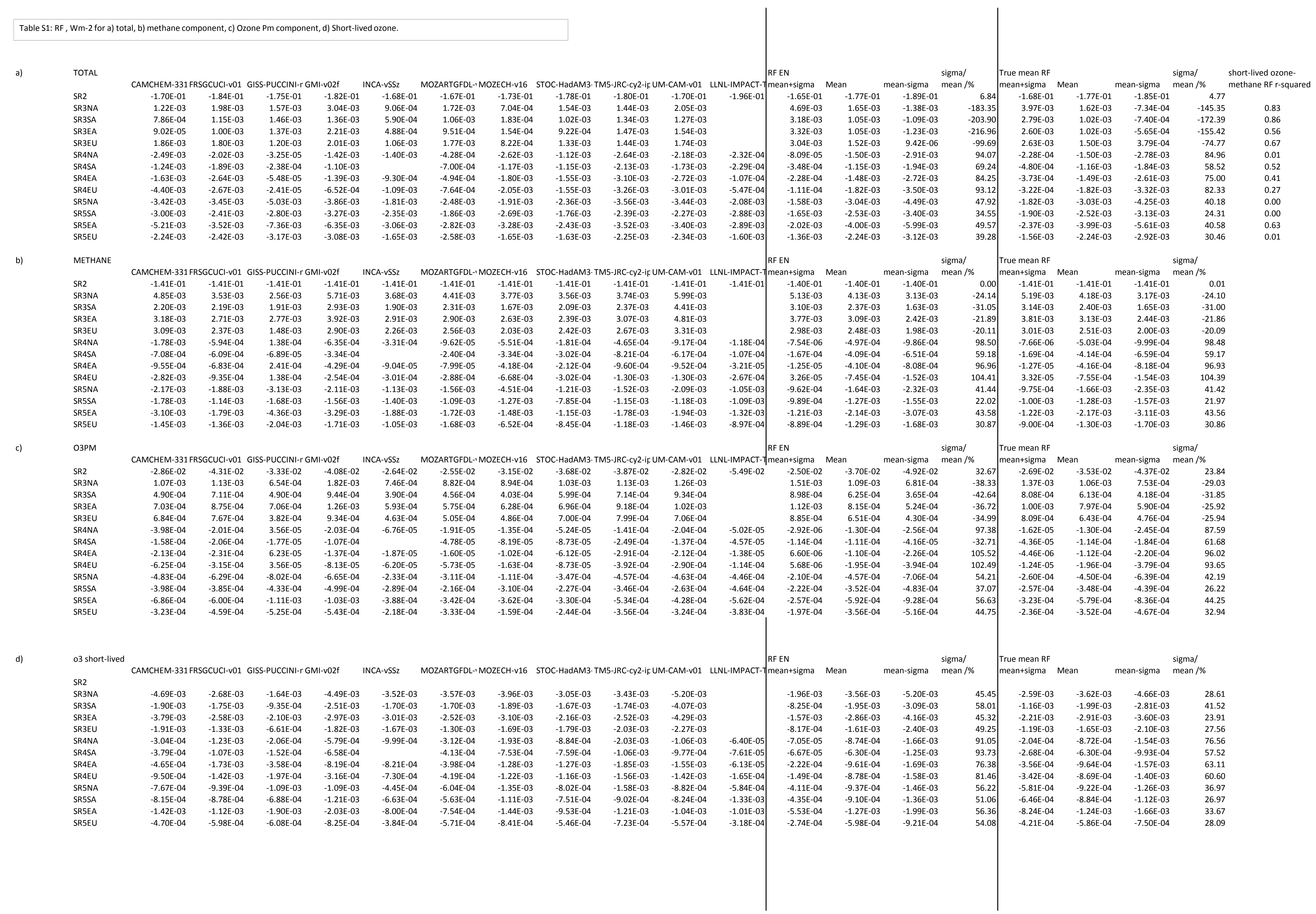


a) TOTAL

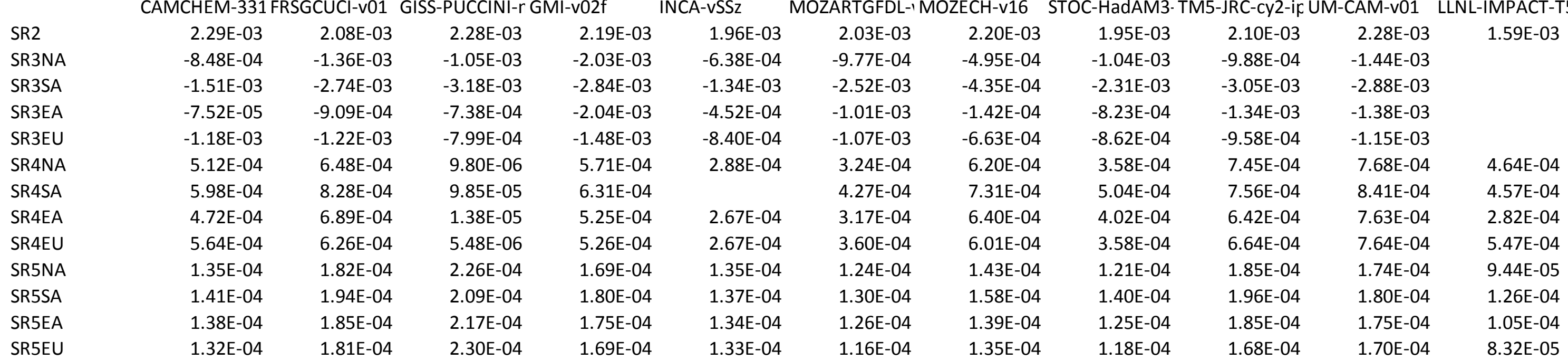

METHANE

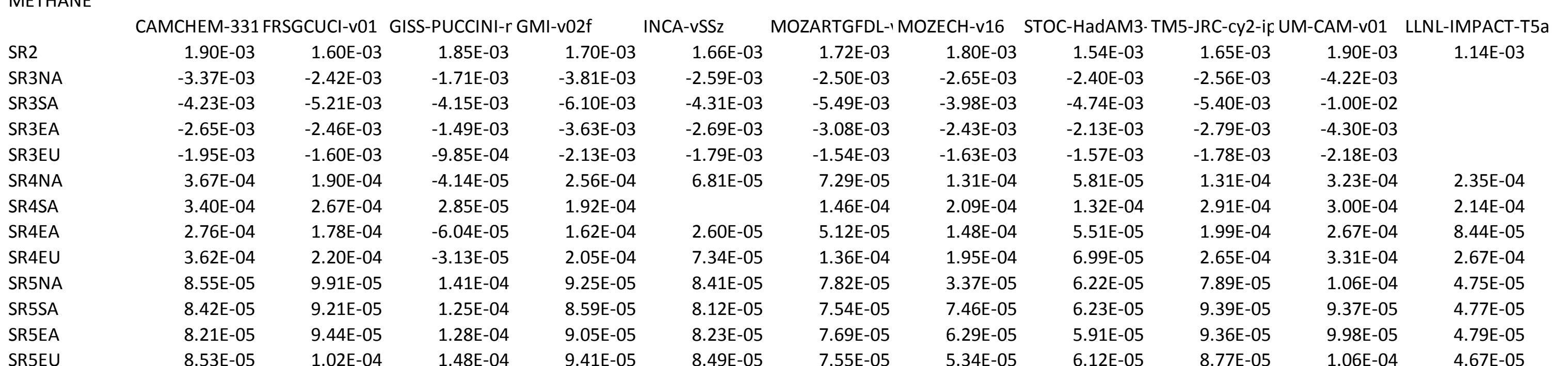

$\begin{array}{llllllllllll}\text { озPM } & 0.999707879 & 0.999883104 & 0.99965581 & 0.999781459 & 0.9997333037 & 0.999772401 & 0.999770573 & 0.999722155 & 0.999787825 & 0.999946219 & 0.999597126\end{array}$

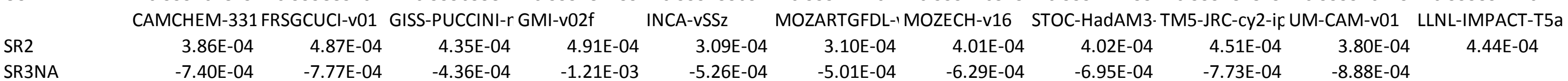

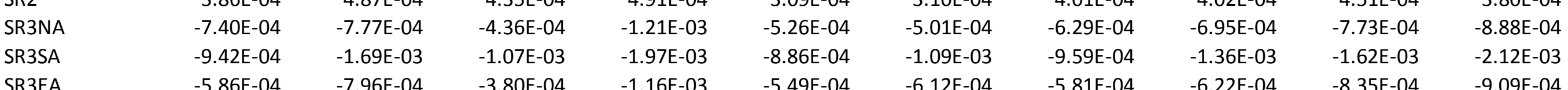

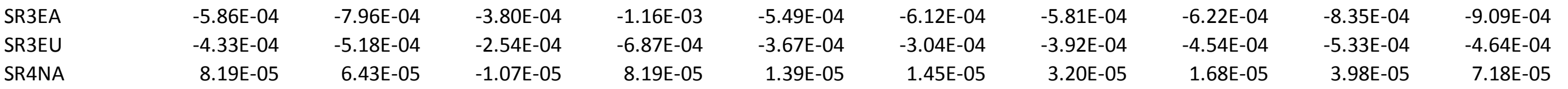

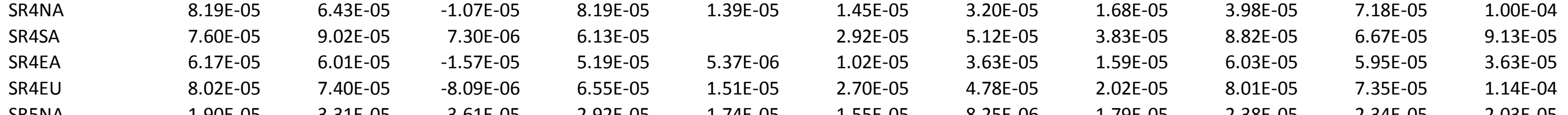

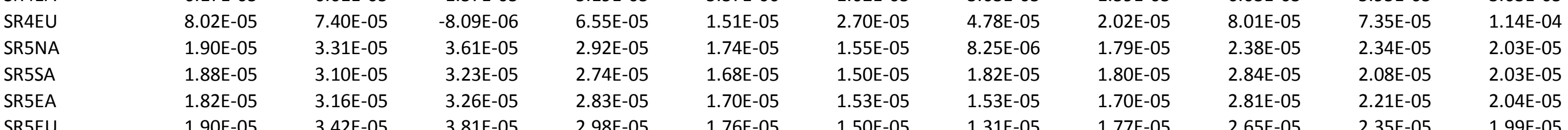

Giss

\begin{tabular}{|c|c|c|c|c|c|c|c|c|c|c|c|}
\hline & & & & & & & & & & & \\
\hline 3SA & $3.66 E-03$ & $\begin{array}{l}4.166-03 \\
\end{array}$ & $2.03 E-03$ & $5.23 E-03$ & $3.866-03$ & $4.055-03$ & $4.511-03$ & 3.796-03 & 3.966-03 & $\begin{array}{l}0.000 \\
9.25 E-03\end{array}$ & \\
\hline & $\begin{array}{l}3.166-03 \\
1.212 E-03\end{array}$ & $\begin{array}{l}2.35 E-03 \\
8.99-0.04\end{array}$ & $\begin{array}{l}1.136-03 \\
4,4=04\end{array}$ & & $\begin{array}{l}2.796-03 \\
1,32 E-0.03\end{array}$ & & $\begin{array}{l}2.877-0.03 \\
1,36 E-0.2\end{array}$ & & 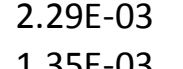 & 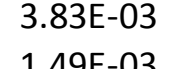 & \\
\hline 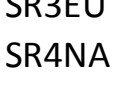 & $\begin{array}{l}1.2121-03 \\
6.25=-05\end{array}$ & $\begin{array}{l}8.98 E-04 \\
3.93 E-04\end{array}$ & 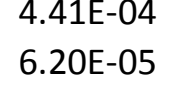 & $\begin{array}{l}1.348 E-03 \\
2.38=-04\end{array}$ & $\begin{array}{l}1.32 E-03 \\
2.06-04\end{array}$ & $\begin{array}{l}7.80 E-04 \\
2.37=-04\end{array}$ & $\begin{array}{l}1.56 t=-04 \\
4.57-04\end{array}$ & $\begin{array}{l}1.1 .162-0.03 \\
2.838-04\end{array}$ & $\begin{array}{l}1.53 t-0.04 \\
5.74 t-04\end{array}$ & $\begin{array}{l}1.49 E-03 \\
3.73 E=04\end{array}$ & \\
\hline & $1.82 E-04$ & $\begin{array}{l}4.70 E-04 \\
0\end{array}$ & $6.288-05$ & $\begin{array}{l}3.788-04 \\
\end{array}$ & & 2.5 & 4 & 44 & 04 & $4.74 E-04$ & \\
\hline & $\begin{array}{l}1.34=-04 \\
12025\end{array}$ & $\begin{array}{l}4.5 \\
.22\end{array}$ & $8.99 E-05$ & 3.7 & $2.36 E-04$ & & $4.55 E-04$ & 84 & $3.83 E-04$ & $4.36 E-04$ & $\begin{array}{l}1.61 E-04 \\
165\end{array}$ \\
\hline & & & & & $3.32 E-0$ & & & & -04 & $106=05$ & \\
\hline & $\begin{array}{l}3.02 E-05 \\
3.84 E-05\end{array}$ & $\begin{array}{l}4.942-05 \\
7.08 E=05\end{array}$ & & $\begin{array}{l}4.77 E-05 \\
6.65-05\end{array}$ & & & & & $\begin{array}{l}8.25 E-05 \\
7.39 E-0.5\end{array}$ & & \\
\hline & 3. & 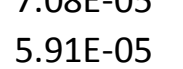 & 5 & 0 & 3.5.51-0.0 & & & & & & It-us \\
\hline & 2.776 & 4.466-00 & $411 E-05$ & I53E-05 & $3.09=-0$ & & & & $=05$ & & \\
\hline
\end{tabular}

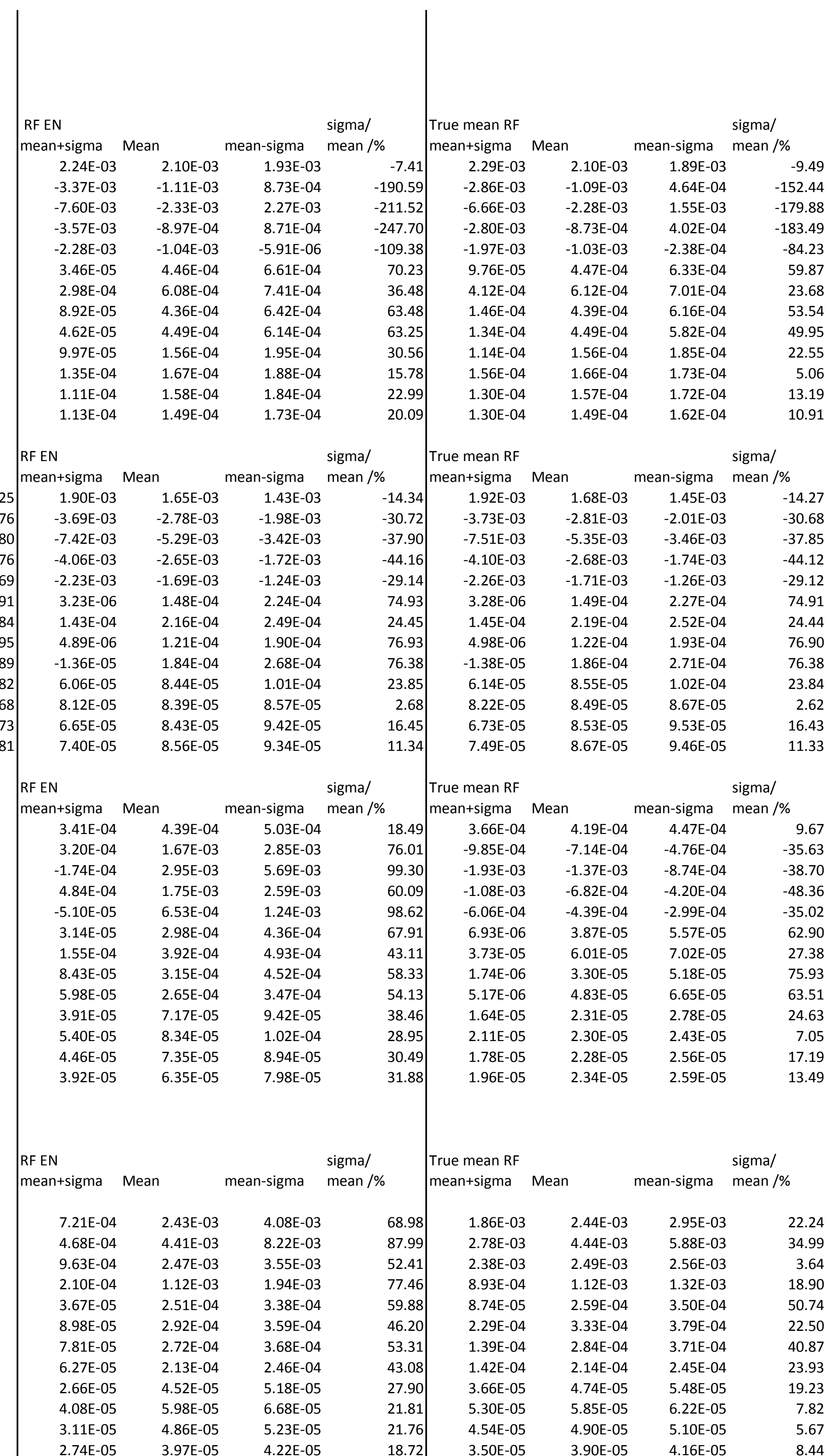




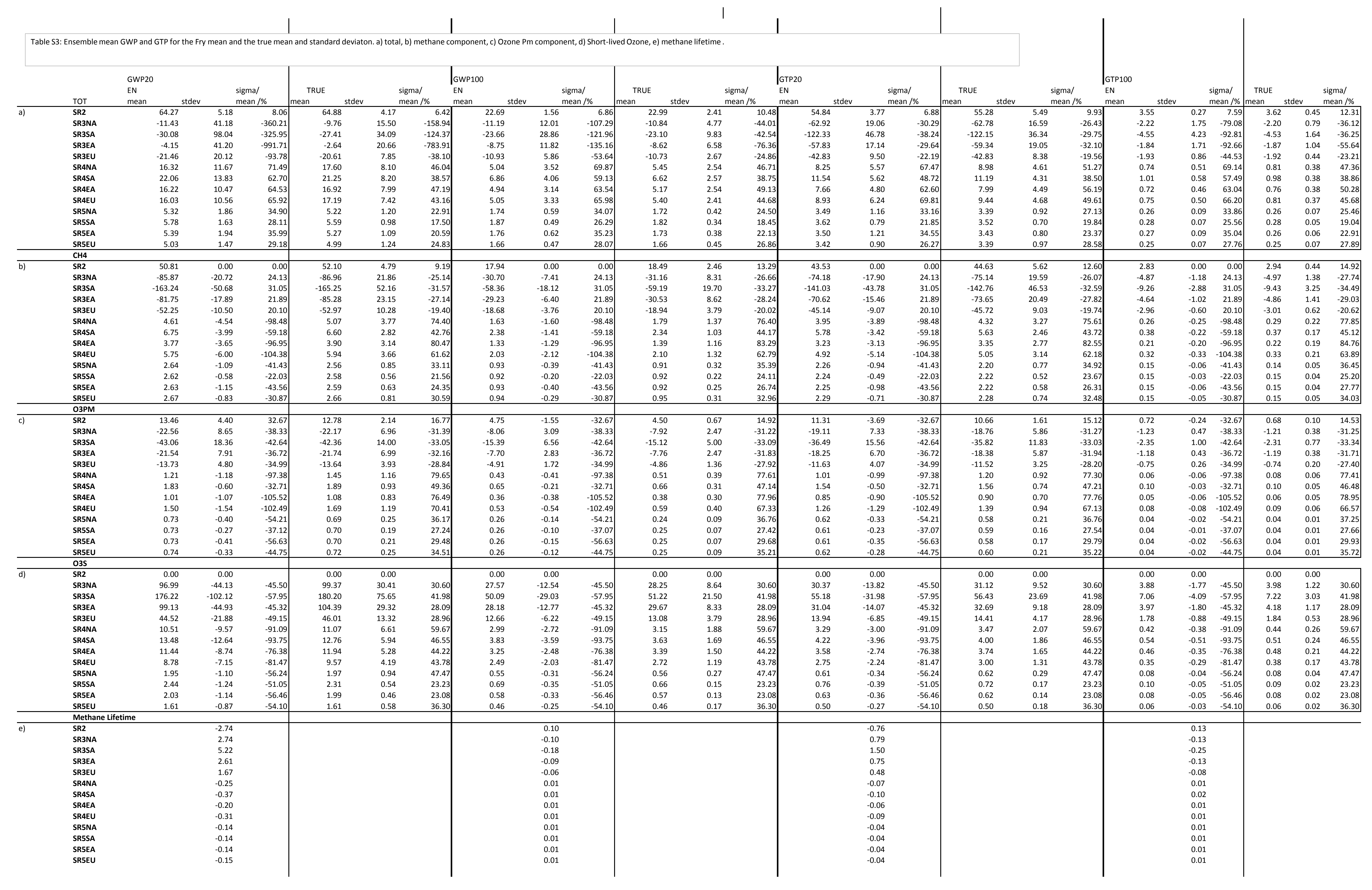

